\title{
"Desespediente»: la máscara mortuoria de la burocracia
}

\section{«Desespediente»: the death mask of bureaucracy}

\author{
Jorge Aguilera López
}

Centro de Enseñanza para Extranjeros, Universidad Autónoma de México, Ciudad de México, México

Seminario de Investigación en Poesía Mexicana Contemporánea jorgeaguileral@hotmail.com

\section{RESUMEN}

El propósito del presente trabajo es realizar un análisis estilístico del poema «Desespediente» de Pablo Neruda, incluido en el libro Residencia en la tierra (1935). A través de dicho análisis, buscamos mostrar que las nociones estéticas de este autor, basadas en la noción de «impureza», implican un trabajo formal que consigue transmitir el ambiente y la percepción de espacio mortuorio con el cual se relaciona el ámbito temático del texto: la rutina burocrática. El trabajo a nivel del lenguaje, así como su particular sistema de adjetivación, posibilitan la lectura desde la forma del poema, más allá de la anécdota vital que da origen al texto. Lo que proponemos entonces es una interpretación que imbrica la posición estética del autor, al menos en esta época, con la voluntad de estilo y el lenguaje particular que caracterizan la obra nerudiana de la época en la cual fue escrito Residencia en la tierra.

1 Maestro en Letras Mexicanas por la UNAM, donde cursa el doctorado en Letras. Fue merecedor de la medalla «Alfonso Caso» al mérito universitario por sus estudios de maestría. Es profesor de tiempo completo del Centro de Enseñanza para Extranjeros de la UNAM. Ha impartido cursos en la Facultad de Filosofía y Letras de la UNAM y en el Posgrado de la Pontificia Universidad Católica de Ecuador. Es miembro fundador del Seminario de investigación en Poesía Mexicana Contemporánea, del cual fue coordinador durante el periodo 2012-2014. Sus líneas de investigación son: la poesía social y política de México y Latinoamérica, las vanguardias literarias latinoamericanas y la crítica sobre poesía.

Artículos suyos han aparecido en diversos libros colectivos. Entre los más recientes están: En la orilla del silencio. Ensayos sobre Alí Chumacero (México, Fondo Editorial Tierra Adentro, 2012), América Diversa. Literatura y memoria (Perú, Editorial Altazor, 2012), Ensayando el ensayo. Artilugios del género en la literatura mexicana contemporánea (México; Eón, El Colegio de Puebla, Grand Valley State University, 2013), Mito y utopía en las literaturas andinas contemporáneas (México, CIALC-UNAM, 2013), Los otros raros (México, El Colegio de San Luis, 2014) e Historia crítica de la poesía mexicana (México, Conaculta y Fondo de Cultura Económica, 2015). Es autor del poemario Glosar rupestre (México, Versodestierro, 2014). 


\section{PALABRAS CLAVE}

Pablo Neruda, Residencia en la tierra, Desespediente, poesía impura

\section{ABSTRACT}

The purpose of this paper is to make an aesthetic analysis of the poem «Desespediente» by Pablo Neruda. This poem is included in the book Residencia en la tierra (1935). Through this analysis, we seek showing how the aesthetic notions of the author, based on the concept of «impurity», that implies a formal work. This conveys the atmosphere and perception of mortuary space to which the subject area of the text relates: bureaucratic routine. The language level and its particular system of adjectives, allows reading the poem itself; beyond the vital story that gives rise to the text. Due to which we propose an interpretation that overlaps the aesthetic position of the author, with the will of style and particular language that characterizes Neruda's work in the time in which Residencia en la tierra' was written.

\section{KEYWORDS}

Pablo Neruda, Residencia en la tierra, Desespediente, impure poetry

Así sea la poesía que buscamos, gastada como por un ácido por los deberes de la mano, penetrada por el sudor y el humo, oliente a orina y a azucena salpicada por las diversas profesiones que se ejercen dentro y fuera de la ley.

Una poesía impura como traje, como un cuerpo, con manchas de nutrición, y actitudes vergonzosas, con arrugas, observaciones, sueños, vigilia, profecías, declaraciones de amor y de odio, bestias, sacudidas, idilios, creencias políticas, negaciones, dudas, afirmaciones, impuestos.

Pablo Neruda, «Sobre una poesía sin purezas», 1935

La poesía de Pablo Neruda, qué duda cabe, es de un registro amplísimo: del amor y la melancolía de Veinte poemas de amor y una canción desesperada (1924) al tono épico del Canto general (1950); del humor de Estravagario (1958) al claro compromiso político de España en el corazón (1937) e Invitación al nixonicidio (1973). Sin embargo, la constante en la obra nerudiana se expresa claramente en el epígrafe anterior: una poesía que, en cualquiera de sus tonos, adquiere una identificación vital con la vida cotidiana, con el hombre de la calle, con todo aquello que casi por definición se halla alejado de lo que la tradición clásica consideraría 
«universo poético». Por supuesto, hablamos de un poeta que, en cuanto tal, trabaja con esta materia prima, pero «hace más. Eleva lo ordinario, le da forma literaria a lo que, por definición, no es literario» (Costa, 1993, p. 70). Con esto, intentamos llamar la atención sobre lo que consideramos la nota distintiva del poema que nos ocupa: «Desespediente» (Neruda, 1999, pp. 309-311) puede leerse como una manifestación poética de esa vida «impura», en que, a la par del uso de un lenguaje coloquial en el nivel léxico, en la cadena sintáctica muda su sentido ordinario, creemos, al recurrir a un criterio de adjetivación que enfatiza la percepción de la experiencia burocrática del sujeto lírico, vista como una experiencia trágica, mortuoria.

Mediante nuestra lectura, tratemos de entender cómo, de un paisaje desolador por tedioso, Neruda consigue crear una expresión literaria eficaz, donde la desazón se transfigura en obra de arte, en testimonio artístico de una experiencia de suyo antiestética. En «Desespediente», la voz burocrática asume un tono lírico para hablarnos del arduo, agreste trabajo oficinesco. Por supuesto, no es que Neruda proponga — no en este poema al menos - llegar a la llamada «poesía conversacional» (vg. Ernesto Cardenal), o a la «antipoesía» (vg. Nicanor Parra). No es este el lugar para clarificar las diferencias entre los membretes mencionados, pero debemos precisar que, para nuestro poeta, de la observación del mundo cotidiano «se desprende el contacto del hombre y de la tierra como una lección para el torturado poeta lírico» (Neruda, 1935). La realidad es influjo primigenio; lo demás, como siempre en el arte, arduo trabajo estético.

En el caso de Residencia en la tierra, libro del poeta chileno al que mayor número de páginas críticas se han dedicado, la confluencia de los dos elementos señalados, lo cotidiano y lo poético, propicia una amalgama que no renuncia a la vitalidad ni al tratamiento artístico; antes bien, encuentra un tono personal, definitorio de su travesía creativa, en el que cede la voz a la expresión de un ánimo que podríamos llamar melancolía crónica. Y es que la experiencia vital tan cara a Neruda como sustento creativo encuentra en Residencia en la tierra un tratamiento estético que linda el hermetismo, como lo asume Amado Alonso (1977), al mismo tiempo que recurre a la fuente primaria del lenguaje coloquial, como bien señala Emir Rodríguez Monegal (1966).

La trama biográfica que sustenta este libro, como ha sido abundantemente documentada, es el inicio de la carrera diplomática del autor en sus estancias como cónsul en diversos países de Asia sudoriental, y su regreso a Chile para partir de allí hacia Buenos Aires y Madrid, donde despuntará su fama poética. En este trayecto, escribe Residencia en la tierra, la primera parte en Asia, la segunda en Chile y Buenos Aires, y la tercera en Madrid. El 
conocimiento de este itinerario ayuda a mejor comprender el sentimiento que inunda Residencia en la tierra, pues en el marco creativo de la obra está el paisaje burocrático, de hastío y desesperación ante la imposibilidad de escapar de la rutina oficinesca que ahoga la potencia humana; "sucede que me canso de ser hombre...», dice Neruda en el que acaso sea el poema más famoso de este libro, «Walking around», colindante con "Desespediente». Y aquí encontramos la primera clave del texto, el título mismo: la desesperación de la vida entre expedientes².

Este poema, a diferencia de otros más «herméticos» (por usar la caracterización de Amado Alonso), presenta una estructura menos difusa a nivel anecdótico, por lo que puede interpretarse como una estructura de cinco partes: la primera cuarteta es la introducción elegiaca, puerta de entrada al inframundo burocrático; las dos cuartetas siguientes fungen como el paseo por ese mundo de «administraciones», "calendarios», «títulos», «demandas» y todo el entorno propio del oficinista; la tercera parte, versos 13 a 26, es el núcleo del poema: la expresión anímica, interiorizada, de ese hastío existencial, condensado en las secuencias léxicas más adelante examinadas; los versos 27 a 32 parecen el lamento final, la certeza de la alienación, la pérdida de todo soplo de vida que pudo salvar al oficinista de su rueda de Ixión; la última parte, versos 33 a 41, sería la amarga aceptación de un destino al que se está condenado, como un tránsito hacia la muerte.

Intentemos elucidar la trama estructural del poema. Estamos frente a un texto construido por versos largos (solo un heptasílabo, la mayoría alejandrinos), por lo que la respiración poética requiere así un arresto mayor que, solo por esta extensión, bien puede traducir la experiencia del sujeto poético; sin embargo, lo que Amado Alonso llama «voluntad de no-forma» en Neruda, creemos, encuentra buen asidero en este texto, en el cual la métrica relativamente regular de los versos resulta más de la búsqueda de una expresión natural del lenguaje poético nerudiano que de una posible intencionalidad del poeta por utilizar dicho molde métrico: «como Pablo Neruda está atacado por el prurito de quebrantar toda ley formal, las leyes formales que podamos descubrir en su poesía son inconscientes, involuntarias y no generales; esto es, tendencias, pero no reglas» (Alonso, 1977, p. 80). De esta forma, en el versolibrismo de este poema debemos buscar el ritmo correspondiente, expresado en la

2 «En cuanto a "Desespediente", el título es un neologismo de Neruda, resultante de un cruce entre las palabras desesperación y expediente. Esta última palabra el poeta la escribía espediente, según viejos y documentados hábitos ortográficos» (Loyola, 2004, p. 28). 
cadena sintáctica, ya no fónica, y particularmente en el sistema de adjetivación señalado ${ }^{3}$.

Un apoyo a la lectura de la trama arquitectónica del poema es la estructura gramatical del mismo. La mayoría de las estrofas presenta un verbo único, expresado generalmente en el primer verso (a excepción de la octava), sea en presente de indicativo o en imperativo (las formas del presente de subjuntivo en la tercera, octava y novena estrofa están en primera persona plural, y pueden interpretarse como variante del imperativo). La primera estrofa se constituye con dos perífrasis perfectivas («está llena» y «está manchado»), pero referidas al mismo sujeto: «la paloma» (en el verso dos, expresado por sinécdoque en «su pecho»), lo que semánticamente sugiere una sola oración. Las estrofas cuarta y sexta repiten el verbo («es», «llega»), pero bien podría elidirse la repetición y aquellas seguir funcionando como una sola unidad sintáctica. La última estrofa utiliza dos verbos («rodad»y «venid»), más variantes semánticas de la acción de traslado propuesta por el hablante que trueque del significado léxico. Estas estrofas-oración tienen entonces un solo predicado extendido al menos durante tres versos más cada uno, lo que propicia un ritmo distendido que acumula significados y densifica el entendimiento de los periodos.

En esta trama verbal, el sujeto de la elocución expresa una actitud particular que varía en cada una de las partes propuestas del poema. En la primera estrofa el sujeto formal de las perífrasis es «la paloma», pero la no-identificación del hablante, el cual se expresa en tercera persona singular, otorga un sentido impersonal a la oración. Por contraste, la segunda y tercera estrofa se presentan en forma imperativa, con la variante ya señalada, y la presencia tácita del hablante en «examinemos» da el tono de inclusión directa de este en la acción referida. Las siguientes tres estrofas vuelven a la enunciación impersonal, aquí plena, en el uso del verbo ser («es», «son») con un vago sujeto en «todo llega». La cuarta y quinta parte sugeridas, en este vaivén gramatical, retoman el imperativo plural, regreso a escena del hablante. Esta oscilación elocutiva, además de apoyo estructural, puede ayudar a percibir mejor el grado de participación del sujeto lírico en la escena planteada: la impersonalidad pone al personaje como sujeto pasivo de una experiencia, al margen de su volición, en tanto que el tono imperativo autorreferencial lo hace partícipe inexorable en grado máximo de la acción planteada.

3 «[En el verso libre] la sintaxis parece tomar la batuta del ritmo, en contra de los pies métricos y su rigurosa alternancia de sílabas fuertes y débiles. ¿Ritmo sintáctico? Así parece» (Paredes, 2004, p. 30). 
Basándonos en la estructura gramatical señalada, se hace evidente la división en cinco partes que hemos propuesto para el poema. Las partes primera (pp. 1-4) y tercera (pp. 13-26), expresadas en forma impersonal, representan la introspección del hablante en la emoción emanada de la realidad; en tanto que las partes segunda (pp. 5-12), cuarta (pp. 2732) y quinta (pp. 33-41) enunciadas en modo imperativo se vuelcan hacia la vivencia explicita de la actividad oficinesca. El ya señalado vaivén gramatical también es emotivo: se parte de la impresión para ir hacia la realidad; se regresa a la consideración patética para finalizar en la vivencia efectiva. El tono general del poema, aunque no formalmente, deja la impresión de un discurso pronunciado por una primera persona plural, que comparte la experiencia y la conmoción con sus colegas de trabajo al mismo tiempo que con el lector: «esto es lo que vivimos día a día», parece decir el autor.

Ahora bien, estas estrofas-oración del poema, según interpretamos, se constituyen sobre la base de una acumulación adjetival, epicentro del redimensionamiento del referente «impuro» al terreno lírico en virtud del arte creativo del poeta. Para intentar explicar este procedimiento, detengámonos en el inventario léxico del poema. Constituido sobre un registro coloquial y con referencias a un ámbito específico, dicho inventario encuentra una subversión estética basada en la adjetivación aplicada a la rutina enunciada por los sustantivos, los cuales están abstraídos del mundo real y llevados a su nueva dimensión estética: «nada más ajeno a sus poemas que el significado habitual de las palabras con que están hechos», escribe Héctor Eandi a Neruda (Aguirre, 1980, p. 53).

La primera parte del poema, como ya señalamos, presenta el escenario en que se mueve el sujeto poético:

La paloma está llena de papeles caídos, su pecho está manchado por gomas y semanas, por secantes más blancos que un cadáver y tintas asustadas de su color siniestro.

La vida, simbolizada por la paloma — «la paloma me parece la expresión más acabada de la vida, por su perfección formal», explica Neruda en una carta a Amado Alonso (1977, p. 228) —, "está llena de papeles caídos» (p. 1), lo que equivale a la identificación del confinamiento burocrático de que es presa el yo lírico. Reparemos en el «color siniestro» de las tintas (p. 4) que ennegrecen el pecho, el cual es, como el papel secante, «más blanco que un cadáver» (p. 3). En esta primera estrofa observamos cuatro frases adjetivas que refieren la impresión emocional de la vida burocrática. De entre esas cuatro, las dos últimas son una caracterización mortuoria de 
esa realidad («cadáver», «color siniestro»), lo cual establece, además, la constante emocional que se irradia a lo largo del texto: la vida burocrática como una experiencia tanática.

Una vez establecido el ambiente, pasamos a la evocación de las actividades burocráticas:

Ven conmigo a la sombra de las administraciones,

al débil, delicado color pálido de los jefes,

a los túneles profundos como calendarios,

a la doliente rueda de mil páginas.

Examinemos ahora los títulos y las condiciones,

las actas especiales, los desvelos,

las demandas con sus dientes de otoño nauseabundo, la furia de cenicientos destinos y tristes decisiones.

En un mundo sombrío de administraciones, jefes, calendarios y páginas interminables (pp. 5-8), se realiza la incesante labor del examen de títulos, actas, demandas, decisiones (pp. 9-12). Nuevamente, en virtud de las cualidades atribuidas a este lenguaje de oficina, se nombra la angustia, el tedio, la desesperanza de la voz poética, y esta emoción doliente se registra mediante el recurso de anteponer la adjetivación, como si se tratara de epítetos ordinarios, pero utilizados aquí para evidenciar su fuerza lírica: «sombra de las administraciones» «débil, color pálido de los jefes» (p. 6), «túneles profundos como calendarios» (p. 7), «doliente rueda de mil páginas» (p. 8), «cenicientos destinos y tristes decisiones» (p. 12); de esta forma se logra percibir primero la emoción que el concepto. En el verso 11, único de esta serie donde el sustantivo aparece en posición focal, la adjetivación se presenta mediante una metáfora que sugiere repulsión («dientes de otoño nauseabundo») y que irradia regresivamente sobre los cuatro sustantivos de los dos versos anteriores - cinco con el del verso en cuestión-, para evitar que pasen sin la caracterización respectiva.

Pasamos así a la parte central del poema:

Es un relato de huesos heridos, amargas circunstancias e interminables trajes, y medias repentinamente serias.

Es la noche profunda, la cabeza sin venas

de donde cae el día de repente como de una botella rota por un relámpago.

Son los pies y los relojes y los dedos y una locomotora de jabón moribundo, 
y un agrio cielo de metal mojado,

y un amarillo río de sonrisas.

Todo llega a la punta de dedos como flores, a uñas como relámpagos, a sillones marchitos, todo llega a la tinta de la muerte y a la boca violeta de los timbres.

El desarrollo de la percepción de esa realidad arroja el saldo de desesperación, ya anunciado en el título. Este tránsito de la acción a la interpretación emocional, expresado en la impersonalidad enunciativa, reitera la relación sustantivo-adjetivo que hemos venido señalando. Sea antepuesta o pospuesta, la cualificación va ratificando verso a verso el sentimiento de desolación del yo lírico: «huesos heridos», "amargas circunstancias», «noche profunda». La vida se desborda hacia la muerte; vale decir, se derrama como algo golpeado por una fuerza superior al sujeto, «como una botella rota por un relámpago» (p. 18). En la quinta estrofa, la experiencia poética nos devuelve un ser fragmentado - acaso reminiscencia cubofuturista, dado el tipo de imagen vanguardista presente en esta-, donde la acumulación de sus partes, sintácticamente expresada por el polisíndeton, no alcanza a dibujarnos una unidad estable, sino solo jirones de esa realidad (pp. 19-22).

La coda de este lamento central —en la estructura del poema y en la sensación percibida- (pp. 23-26) vuelve al escenario del oficinista, donde será también la expresión fragmentada del entorno lo que acentúe la desazón del sujeto poético. Los «dedos» y las «uñas» de las secretarias (pp. 23-24), tanto como los «sillones marchitos» (p. 24), constituyen ese punto insalvable de la rutina: el diario regreso a la actividad laboral, presentada desde los primeros versos, el escenario fúnebre antes destacado, y ahora crudamente expresado: «todo llega a la tinta de la muerte» (p. 25), donde hasta la actividad más trivial, como pegar estampillas, tiene sabor a defunción, por lo que deja la «boca violeta», lo mismo que un cadáver.

En la cuarta parte del poema, asistimos a la despedida del mundo de los placeres sensibles, mediante una expresión poética que no alcanza a nombrar el todo, por lo que el recurso de la sinécdoque refuerza la desazón de esas partes que se alejan con el inagotable discurrir del hartazgo:

Lloremos la defunción de la tierra y el fuego, las espadas, las uvas, los sexos con sus duros dominios de raíces, las naves del alcohol navegando entre naves 
y el perfume que baila de noche, de rodillas, arrastrando un planeta de rosas perforadas.

Estamos lejos de la aventura («espadas»), del vino («uvas») ${ }^{4}$, del goce sexual; paisaje yerto, introducido en ese llanto por la «defunción» del mundo exterior (p. 27), extraño al escenario al que indefectiblemente habrá de volver, cual Ixión, en ese girar incesante de la rueda de su Hades burocrático. Todavía el último verso de esta sétima estrofa presenta una imagen sorprendente: «planeta de risas perforadas» (p. 32), que se constituye a partir de una estructura sustantivo-frase adjetiva, y esta a su vez compuesta por un sustantivo y un adjetivo. En otras palabras, el resultado final de la trama cualitativa resalta el carácter sorpresivo de la imagen señalada.

La parte final del texto resulta, en esta travesía del sujeto lírico, el regreso a la repetición ad nauseam de la monotonía lúgubre, con el agregado de la certeza de una progresiva e implacable deshumanización: «con un traje gris de perro» (p. 33):

Con un traje de perro y una mancha en la frente caigamos a la profundidad de los papeles, a la ira de las palabras encadenadas, a manifestaciones tenazmente difuntas, a sistemas envueltos en amarillas hojas.

Rodad conmigo a las oficinas, al incierto olor de ministerios, y tumbas, y estampillas. Venid conmigo al día blanco que se muere (40) dando gritos de novia asesinada.

Esta sima de «papeles», «palabras encadenadas» y «amarillas hojas» no son otra cosa que los múltiples rostros de la desesperanza; «manifestaciones tenazmente difuntas» (p. 36) las nombra la voz poética para expresar la identificación mortuoria de la experiencia oficinesca. Al final, solo el grito, la llamada de auxilio ante este abismarse del día en el inframundo de la oficina, ese día que ya no pudo ser, tal como una «novia asesinada» (p. 41).

A lo largo del texto, como ritornello temático, encontramos una constante caracterización mortuoria de la rutina oficinesca, la cual se transfigura experiencia lírica en virtud de dicho tratamiento: de tal suerte, el

4 Sobre el significado de los sustantivos espadas y uvas en el contexto de Residencia en la tierra, Alonso (1977), cap. VII, «Sobre la índole de la fantasía poética de Pablo Neruda», en especial las pp. 245-249 y pp. 256-258. 
recurso poético cifrado en la reiteración del motivo fúnebre es lo que da fuerza, paradójicamente, vital al poema. Sea expresado mediante palabras denotativas (cadáver, moribundo, muerte, defunción, difuntas, muere, asesinada) o por términos que connotan tal idea (color siniestro, otoño nauseabundo, huesos heridos, cabeza sin venas, boca violeta, rosas perforadas), el poema nos deja la impresión de que la actividad burocrática es una progresiva degradación de la potencia humana, y el tono funesto caracteriza al sujeto poético en su expresión emotiva.

Tal es la «impureza» que caracteriza a este poema. Ajeno a los dictados de «el arte por el arte» ${ }^{5}$, el autor de Residencia en la tierra no rehúye a hablar del mundo inmediato, a imbricar sus vivencias en la obra de arte, como ha demostrado Emir Rodríguez Monegal (1966): «Hablo de cosas que existen, Dios me libre / de inventar cosas cuando estoy cantando!», escribe en otro poema de Residencia en la tierra: «Estatuto del vino» (Neruda, 1999). La destreza de Neruda en el manejo del lenguaje asociado a la vida diaria no resulta ajena a «Desespediente»: exceptuando el título, que bien mirado no es sino el cruce de dos palabras ordinarias, el resto del poema se deja leer, a nivel léxico, sin mayores complicaciones. Es entonces que volteamos la mirada no al registro lingüístico, sino al modo en que se desenvuelven estas palabras en el interior del texto; de esta manera descubrimos los recursos que dotan de eficacia estética al poema, en esta forma particular de adjetivación, eficacia creativa del poeta para transgredir los lazos semánticos del lenguaje común —lenguaje hecho de impurezas-, como esperamos haber demostrado. 


\section{REFERENCIAS BIBLIOGRÁFICAS}

Aguirre, M. (1980). Pablo Neruda Hector Eandi. Correspondencia durante Residencia en la tierra. Buenos Aires: Editorial Sudamericana.

Alonso, A. (1977). Poesía y estilo en Pablo Neruda. Buenos Aires: Editorial Sudamericana.

Costa, R. de. (1993). La poesía de Pablo Neruda. Santiago de Chile: Editorial Andrés Bello.

Loyola, H. (2004). Lo que el más grande amor. Sobre Eros y Tánatos en Neruda. Atenea, 489 , pp. 23-36.

Neruda, P. (1935). Presentación. Caballo Verde para la Poesía, 1.

berg y Círculo de Lectores.

(1999). Obras completas I. Barcelona: Galaxia Guten-

Paredes, A. (2004). Una temporada de poesía. 9 poetas mexicanos recientes (1966-2000). México D. F.: Conaculta.

Rodríguez Monegal, E. (1966). El viajero inmóvil. Introducción a Pablo Neruda. Buenos Aires: Losada. 